\title{
Knowledge and practice of the prevention of mother-to-child transmission of HIV guidelines amongst doctors and nurses at Odi Hospital, Tshwane District
}

\author{
Kingsley Ogbonna ${ }^{a}$, Indiran Govendera* and John Tumbo ${ }^{a}$

\begin{abstract}
${ }^{a}$ Department of Family Medicine and Primary Health Care, Sefako Makgatho Health Sciences University (SMU), Pretoria, South Africa
\end{abstract} \\ *Corresponding author, email: Indiran.govender@gmail.com
}

\begin{abstract}
Background: Almost 60 million people are infected with and 25 million people have already died from HIV/AIDS. Sub-Saharan Africa is the region most affected, with $67 \%$ of all people living with HIV and $91 \%$ of all new infections amongst children and 14 million children orphaned by HIV-related deaths. HIV can be transmitted from a pregnant mother to her child during pregnancy, birth or breastfeeding. In South Africa (SA) the mother-to-child HIV transmission (MTCT) rate is under $4 \%$ at 4 to 8 weeks after birth since implementation of the most recent national prevention of MTCT (PMTCT) programme.

Aim: This study sought to investigate the level of knowledge of nurses and doctors working at Odi Hospital in Tshwane, and whether they were putting the current PMTCT programme into practice.

Methods: A descriptive cross-sectional survey was undertaken using self-administered questionnaires developed from the current PMTCT guidelines.

Results: Of the 102 participants, 12 (12\%) were doctors and 90 (88\%) nurses, of whom 9 (9\%) were male and 93 (91\%) female. Mean knowledge percentage was $60.8 \%$ and mean practice percentage was $77 \%$. Regarding knowledge, the question on HIV counselling and testing scored an average $93.1 \%$, while that on doses of drugs used in the PMTCT guidelines scored $17.7 \%$. For practice questions scores ranged from $71 \%$ to $82 \%$.

Conclusion: Nurses and doctors working at Odi Hospital knew that HIV counselling and testing is important and must be done for all mothers; however, they were unsure of the dosages of drugs used for PMTCT. More than two-thirds of the doctors and nurses reported practising the PMTCT guidelines, but as their knowledge was inadequate their practice may not be appropriate.
\end{abstract}

Keywords: AIDS, Anti retroviral drugs, doctors and nurses, HIV, prevention of mother to child transmission

\section{Introduction}

Human immune deficiency virus (HIV)/acquired immune deficiency syndrome (AIDS) is a major public health problem globally, with more than 36.7 million people estimated to be living with HIV in 2015 - an increase from 33.6 million in 2013. ${ }^{1}$ The sub-Saharan region of Africa has a disproportionately high number of persons infected with HIV. ${ }^{2}$ The high infection rates are prevalent in both adults and children. In sub-Saharan Africa 260000 children contracted HIV in 2013, with more than $90 \%$ of cases occurring through mother-to-child transmission (MTCT).

The trend of new childhood HIV infections has been declining worldwide, with 150000 children newly infected with HIV in 2015,

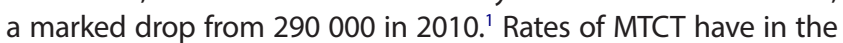
past been reported to be as high as $8-9 \%$, mainly in the underdeveloped countries. ${ }^{1}$ Concerted efforts at reducing MTCT have resulted in rates below $1 \%$ in resource-rich countries. However, this has not been realised in many resource-limited countries due to multiple challenges, which include competing health priorities and limited human and financial resources. ${ }^{3}$ It is also evident that many countries failed to achieve the two important related Millennium Development Goals (MDGs), namely to reduce child mortality and to combat HIV/AIDS, malaria and other diseases by 2015. ${ }^{4}$ These priorities have been included in the Sustainable Development Goals (SDGs), with similar targets to be achieved by $2030 . .^{5}$

There have been changes in the prevention of mother-to-child transmission (PMTCT) guidelines in South Africa (SA) in order to ensure the attainment of these SDG goals. The PMTCT guidelines published by the National Department of Health and South African National AIDS Council in 2010 address the key modalities of HIV transmission from mother to child during pregnancy, the birth process, or through breastfeeding. ${ }^{6}$ According to the guidelines, prevention of transmission of HIV from mother to child has four elements: primary prevention of HIV amongst women of childbearing age; preventing unintended pregnancies amongst women living with HIV; preventing HIV transmission from a woman living with HIV to her infant; and providing appropriate treatment, care and support to women living with HIV, their children and families.

Several studies have shown that the use of antiretrovirals (ARVs) for PMTCT have significantly reduced perinatal HIV transmission if well implemented. ${ }^{78}$ In SA between 2008 and 2011 the estimated proportion of HIV-exposed infants younger than 2 months who underwent routine tests to detect early HIV transmission increased from $36.6 \%$ to $70.4 \% .{ }^{9}$ The estimated HIV transmission rate decreased from $9.6 \%$ to $2.8 \%{ }^{9}$

To implement the PMTCT programme effectively and combat MTCT it is necessary for healthcare professionals to have adequate knowledge of and comply with the implementation of the guidelines. The practice and attitude of these health workers will depend on how much of this knowledge they have and how often they update their knowledge. Reports from rural India indicate that there is willingness by healthcare providers to care for patients with HIV, but this is hampered by concerns regarding ability to provide such care due to resource constraints. ${ }^{10}$

It has also been demonstrated that health education interventions and social systems have positively influenced the behaviour of HIV-infected pregnant women towards PMTCT, and implementation of thePMTCT programme, and the comprehensive 
HIV/AIDS management and treatment plan has made some progress towards alleviating the burden of paediatric HIV in SA. ${ }^{11,12}$

Odi Hospital is a 197-bed district hospital situated north of Tshwane in Gauteng Province and serves a population of 524000 people. The hospital provides comprehensive obstetric and child health services on an outpatient and inpatient basis. The prevalence of HIV amongst antenatal women in the region has been reported to be $24.4 \% .^{13}$ The MTCT rate amongst users of Odi Hospital is reported to be $1.84 \%,{ }^{14}$ and the reasons for this high rate of MTCT have not been established.

The aim of our study was to assess the knowledge and practice of doctors and nurses in Odi Hospital regarding the PMTCT programme, with a view to improving performance through targeted interventions.

\section{Research methods and design}

A descriptive cross-sectional study was conducted amongst doctors and nurses working at Odi Hospital. All 31 doctors and 180 professional nurses working in the hospital were included in the study, as they all work in the obstetric unit on a rotational basis.

Data were collected using a self-administered questionnaire written in English. The questionnaire was developed from the South African PMTCT guidelines and piloted in another district hospital in the same region. The questions covered pre-test counselling, HIV testing, the various regimens recommended in the national PMTCT guidelines, the doses of the medications, and the indications for initiating ARVs. A biostatistician and an expert in HIV medicine were consulted in drawing up the questionnaire. Informed consent was obtained from each participant. Anonymity and confidentiality were maintained by ensuring that participants' names, addresses or duty posts were not reflected on the questionnaires.

Data were captured by a trained data clerk onto an Excel ${ }^{\oplus}$ spreadsheet (Microsoft Corp, Redmond, WA, USA) and verification was carried out by the statistician. Descriptive data analysis was done by the statistician using the statistical package program $\mathrm{SAS}^{\circledR}$, release 9.2 (SAS Institute, Cary, NC, USA). The demographic profiles of the doctors and nurses were summarised descriptively. Knowledge and practice of the PMTCT programme was assessed per respondent by counting the number of correct answers to the questions regarding knowledge and practices separately and expressing these as a percentage of the total number of questions. A regression analysis was performed with gender, profession, additional qualifications, and years of practice as predictor variables for knowledge of PMTCT.

Permission to conduct the study was obtained from the Chief Executive Officer of Odi Hospital, Tshwane. Ethical clearance was obtained from the MEDUNSA research and ethics committee (MREC), project number MREC/M/162/2013: PG.

\section{Results}

Of the 211 questionnaires sent out, 124 were completed and returned (58.8\% response rate) (Table 1 ).

The majority of participants (80.6\%) were nurses, and $41 \%$ of these were recorded as professional nurses. There were more female $(86.3 \%)$ than male respondents, while $32 \%$ of the respondents had post-basic qualifications (master's degree, diploma and certificates in various fields). The mean duration of practice for all participants was $12.7( \pm 7.21)$ years (Table 2 ).
Table 1: Demographic characteristics of respondents

\begin{tabular}{|c|c|}
\hline Characteristic & No. \\
\hline \multicolumn{2}{|l|}{ Sex } \\
\hline Male & 17 \\
\hline Female & 107 \\
\hline Total & 124 \\
\hline \multicolumn{2}{|l|}{ Designation } \\
\hline Doctor & 24 \\
\hline Professional nurse & 41 \\
\hline Enrolled nurse & 43 \\
\hline Enrolled nursing assistant & 16 \\
\hline Total & 124 \\
\hline \multicolumn{2}{|l|}{ Basic qualification } \\
\hline Bachelor's degree & 26 \\
\hline Diploma & 37 \\
\hline Tertiary certificate & 48 \\
\hline School certificate & 13 \\
\hline Total & 124 \\
\hline \multicolumn{2}{|l|}{ Post-basic qualification } \\
\hline Master's degree & 2 \\
\hline Diploma & 9 \\
\hline Certificate & 2 \\
\hline Total & 13 \\
\hline \multicolumn{2}{|l|}{ Years of clinical practice } \\
\hline$<5$ & 12 \\
\hline $5-9$ & 34 \\
\hline $10-14$ & 26 \\
\hline $15-19$ & 18 \\
\hline$\geq 20$ & 28 \\
\hline Total & 118 \\
\hline
\end{tabular}

Respondents had high levels of knowledge (94\%) regarding HIV counselling and testing (HCT) as the first step in the PMTCT programme. They equally knew the criteria for initiation of antiretroviral therapy (ART) in all HIV-positive pregnant women and would not hesitate to initiate ART in patients. Conversely, combination and doses of medications were a challenge, as most participants did not have satisfactory knowledge of these $35 \%$ and $21 \%$ correct responses respectively). Doctors were more knowledgeable about HIV and PMTCT than nurses (mean scores $79 \%$ and $58 \%$ respectively).

The practices of PMTCT amongst doctors and nurses were noted to be satisfactory. When dealing with a pregnant woman who presents late, respondents exhibited a high level of awareness and willingness to offer them HCT/voluntary counselling and testing (VCT), as well as to treat those known to be HIV-positive as they progressed in their pregnancy. The approach to the newborn of an HIV-positive pregnant woman was fair amongst participants, as $71 \%$ took the correct steps (Table 3).

Profession and the mean years of practice (experience) amongst doctors and nurses were found to have a statistically significant $(p<0.05)$ association with knowledge about PMTCT. The mean knowledge of doctors (79.2\%) was significantly higher than that of nurses $(58.4 \%)(p<0.001)$. 
Table 2: Respondents' knowledge and practice of PMTCT programme

\begin{tabular}{|c|c|c|c|c|}
\hline Attribute & Variable & Response & $\begin{array}{l}\text { Number } \\
(n=124)\end{array}$ & $\begin{array}{c}\text { Proportion } \\
\text { (\%) }\end{array}$ \\
\hline \multirow{5}{*}{ Knowledge } & Procedure & $\begin{array}{l}\text { Correct initial } \\
\text { procedural } \\
\text { step }\end{array}$ & 117 & 94.4 \\
\hline & Procedure & $\begin{array}{l}\text { Correct } \\
\text { subsequent } \\
\text { procedural } \\
\text { step }\end{array}$ & 107 & 86.3 \\
\hline & Medication & $\begin{array}{l}\text { Correct } \\
\text { combination } \\
\text { of medicines } \\
\text { for PMTCT }\end{array}$ & 43 & 34.7 \\
\hline & Medication & $\begin{array}{l}\text { Correct } \\
\text { dosages of } \\
\text { medicine }\end{array}$ & 26 & 21 \\
\hline & Medication & $\begin{array}{l}\text { Correct } \\
\text { indication for } \\
\text { ARVs }\end{array}$ & 102 & 82.3 \\
\hline \multirow{4}{*}{ Practice } & Screening & $\begin{array}{l}\text { Correctly } \\
\text { performs HIV } \\
\text { test }\end{array}$ & 100 & 80.6 \\
\hline & Intervention & $\begin{array}{l}\text { Correctly } \\
\text { cares for } \\
\text { pregnant } \\
\text { woman pre- } \\
\text { senting late }\end{array}$ & 102 & 82.3 \\
\hline & Intervention & $\begin{array}{l}\text { Correctly } \\
\text { cares for } \\
\text { HIV- negative } \\
\text { pregnant } \\
\text { woman }\end{array}$ & 93 & 75 \\
\hline & Intervention & $\begin{array}{l}\text { Correctly } \\
\text { cares for } \\
\text { HIV- exposed } \\
\text { newborn }\end{array}$ & 88 & 71 \\
\hline
\end{tabular}

Table 3: Association between respondents' demographic characteristics and knowledge and practice of PMTCT

\begin{tabular}{|c|c|c|c|c|}
\hline Factor & $n(\%)$ & $\begin{array}{l}\text { Mean }( \pm S D) \text { of } \\
\text { correct answers }\end{array}$ & t-test & $p$-value \\
\hline \multicolumn{5}{|l|}{ Practice } \\
\hline Males & $17(14 \%)$ & $76.5( \pm 27.20)$ & \multirow{2}{*}{0.027} & \multirow{2}{*}{0.979} \\
\hline Females & 107 (86\%) & $76.6( \pm 24.10)$ & & \\
\hline Doctors & 24 (19\%) & $75.0( \pm 30.40)$ & \multirow{2}{*}{0.359} & \multirow{2}{*}{0.720} \\
\hline Nurses & $100(81 \%)$ & $77.0( \pm 22.94)$ & & \\
\hline \multicolumn{5}{|l|}{ Knowledge } \\
\hline Males & $17(14 \%)$ & $63.5( \pm 19.02)$ & \multirow{2}{*}{0.216} & \multirow{2}{*}{0.829} \\
\hline Females & $107(86 \%)$ & $62.3( \pm 23.36)$ & & \\
\hline Doctors & $24(19 \%)$ & $79.2( \pm 23.20)$ & & \multirow{2}{*}{$0.001^{*}$} \\
\hline Nurses & $100(81 \%)$ & $58.4( \pm 22.83)$ & & \\
\hline \multicolumn{5}{|c|}{ Years of practice } \\
\hline Males & $15(13 \%)$ & $13.9( \pm 9.11)$ & \multirow{2}{*}{0.701} & \multirow{2}{*}{0.484} \\
\hline Females & $103(87 \%)$ & $12.5( \pm 6.91)$ & & \\
\hline Doctors & $22(19 \%)$ & $9.7( \pm 8.79)$ & \multirow{2}{*}{2.22} & \multirow{2}{*}{$0.028^{*}$} \\
\hline Nurses & $96(81 \%)$ & $13.41( \pm 6.66)$ & & \\
\hline
\end{tabular}

A regression analysis was also performed with profession, additional qualifications and years of experience as predictor variables for practice of PMTCT. No other significant predictors were found. The mean percentages of doctors and nurses who practised the PMTCT guidelines correctly $(75.0 \%$ and $77.0 \%$ respectively) did not differ significantly $(p=0.72)$.

\section{Discussion}

There were $17(14 \%)$ male and 107 (86\%) female participants, amongst whom there were 24 (19\%) doctors and 100 (81\%) nurses. This is similar to the findings of a report on demographic characteristics of health professionals in the United States of America, which showed that about $95 \%$ of professional nurses were females. ${ }^{15}$ Some $32 \%$ of the study sample had an additional qualification, and the mean years of practice for all participants was $12.7( \pm 7.21)$.

In this study the mean knowledge scores for doctors and nurses were $79 \%$ and $58 \%$ respectively, which is in keeping with a study by Umeh et al. (2008), which concluded that healthcare workers (HCWs) knew PMTCT fairly well, with doctors having the highest mean knowledge score of 18.43 compared with nurses and laboratory scientists at 13.9 and 11.01 respectively. ${ }^{16}$

Respondents reported correct practices in the care of newborns of HIV-positive pregnant women, with $71 \%$ taking the correct steps. This agrees with Amoran et al. (2012), who studied homebased care practices of HCWs concerning HIV/AIDS patients and found that $70 \%$ practised the relevant aspects of home-based care for those with HIV/AIDS correctly. ${ }^{17}$

No significant differences were found between male and female respondents or doctors and nurses in terms of practising the PMTCT guidelines ( $p=0.0979$ and 0.0720 respectively). There was, however, a significant difference between the knowledge level of doctors and nurses $(p=0.001)$, as well as in the years of practice of doctors and nurses $(p=0.028)$. This corresponds with the findings of Nneka and Donna (2007) and Hentgen et al. (2002), who showed that doctors demonstrated a better knowledge of HIV/AIDS-related issues than nurses. ${ }^{18,19}$

There was a significant difference in knowledge between the professions in terms of years of practice $(p=0.028)$. This is in agreement with Ndikom and Onibokin (2007), who showed a direct relationship between previous care of HIV-infected patients and better knowledge. ${ }^{20}$ In total, $94 \%$ of all participants knew the first step of the PMTCT programme correctly to be HCT or VCT. Participants generally performed well on this aspect of knowledge of the PMTCT programme. In a 2006 study carried out on health workers, good knowledge of sexual intercourse amongst others as a route of transmission of HIV was demonstrated by participants. ${ }^{21}$ Similarly, Pokharel, Shrestha and Lama (2011) revealed that about $70 \%$ of stakeholders knew that unprotected sexual intercourse with an HIV-infected person could lead to transmission of the virus. ${ }^{22}$ In that study participants identified awareness of HIV status of pregnant women as an effective way of minimising MTCT, mostly because sexual intercourse as a mode of transmission and determining the HIV status of an individual are vital aspects of and practical steps in VCT. This can be compared with the study of Hentgen et al., in which knowledge of important aspects of VCT was found to be poor. $^{19}$

Knowledge of criteria for initiation of ART was good amongst the doctors and nurses in this study. It is important that HCWs know when to start ART for PMTCT purposes. The Drug Resource Enhancement against Malnutrition (DREAM) study showed MTCT of $1.2 \%$ amongst breastfed infants and $0.8 \%$ in formula-fed 
infants when correct knowledge and practices are followed. ${ }^{23}$ MTCT rates were $4.1 \%$ at six weeks and $5 \%$ at six months of age, if PMTCT is properly followed. In the index survey participants' responses were $86 \%$ correct. This may be due to the recent PMTCT guidelines, which provided for initiation of ART in all HIVpositive pregnant women, irrespective of their CD4 count. This is in keeping with $83 \%$ to $95 \%$ overall knowledge of PMTCT amongst HCWs according to Harms et al. (2005). ${ }^{24}$

Miyani and McIntyre (2013), however, revealed otherwise in a study carried out in Soweto, in which HCWs had poor knowledge as well as practice of PMTCT. ${ }^{25}$ A mean score of 5.15 (SD \pm 1.85 ) was obtained for PMTCT knowledge amongst HCWs. Poor remuneration, increased workload and poor staffing were adverse factors challenging their work. Among stakeholders (health personnel and female health volunteers), $61 \%$ had poor knowledge of PMTCT, while $8 \%$ of the HCWs knew that postpartum administration of ARV medicine to a newborn reduces infection, and only $38 \%$ referred patients to a PMTCT facility. ${ }^{22}$

Participants showed very poor knowledge of medication combinations and their doses, at $35 \%$ and $21 \%$ correct responses respectively. This may be due to the frequent changes in the national PMTCT guidelines. A 2007 study by Olges et al. ${ }^{26}$ showed correct practices amongst HCWs in managing HIV-positive pregnant women coming for their first antenatal consultation; this is further seen in this study, in which $81 \%$ responded correctly by providing PMTCT intervention to HIV-positive pregnant women at their first antenatal consultation. A threedrug regimen which contains a non-nucleoside reverse transcriptase inhibitor or a protease inhibitor leads to a lower than $5 \%$ transmission rate at birth in poor countries and even less in rich countries. Shapiro et al. (2010) showed an overall transmission rate of $0.8 \%$ at birth amongst three treatment groups. ${ }^{27}$ These rate reductions occur when the PMTCT guidelines are applied correctly. Arendt et al. (2007) revealed an MTCT rate of $1.4 \%$ at birth..$^{28}$

There have been previous studies that determined overall PMTCT knowledge. In rural India HCWs had poor knowledge of PMTCT and hence practised it incorrectly. Hentgen et al. (2002) carried out a study in Madagascar towards introducing a VCT programme, and found that the providers had poor knowledge to sustain it. ${ }^{19}$ In that study $73 \%$ of the HCWs were unaware of interventions to reduce MTCT of HIV, and therefore thought that transmission to the baby was certain. In our study the mean knowledge for doctors was $79 \%$ and for nurses was $58 \%$; this may be due to the deficiency of additional qualifications as reported by participants. This agrees with the findings of Nneka and Hentgen et al. (2002), who showed that doctors were more knowledgeable than nurses concerning PMTCT. ${ }^{18,19}$

The questionnaire addressed the practices amongst participants in an open-ended fashion, and aimed at getting the participants to apply their knowledge as per the national PMTCT guidelines. The aspects covered were scenarios that presented as dilemmas. The risk of MTCT of HIV varies between $15 \%$ and $45 \%$ with interventions in terms of PMTCT. ${ }^{29}$ Maternal plasma viral load, breast milk viral load, and immunological and clinical status of the mother play a significant part in PMTCT. Jamieson et al. (2003) and Shaffer et al. (1999) have shown an association between MTCT and maternal viral load. Hence a good knowledge of this correlation will empower an HCW to take appropriate steps when attending to an HIV-positive woman during her first antenatal visit. ${ }^{30,31}$ Women who had a lower or undetectable viral load (< 50 copies $/ \mathrm{ml}$ ) close to childbirth had lower transmission rates $(0.09 \%)$ compared with those with higher viral load ranges (400-999 copies $/ \mathrm{ml}$ ), who had an MTCT rate of $2.6 \% .^{32}$

In this study the participants scored fairly well (about 70\%) in the scenarios involving pregnant women and their babies: $81 \%$ were aware of what to do during the first antenatal visit and $82 \%$ practised correctly when an unbooked pregnant woman delivers in their facility. They did not hesitate to offer HCT and start ART if the woman was HIV positive. Although this study did not address willingness to provide PMTCT intervention, the respondents demonstrated such willingness. This was not the case in a study by Msiri, Tadesse and Muula (2008), in which $37 \%$ of the respondents were not comfortable attending to an HIV-positive pregnant woman in labour. ${ }^{33}$ A 2007 study by Olges et al. ${ }^{26}$ showed correct practices amongst HCWs in managing HIVpositive pregnant women coming for their first antenatal consultation. Furthermore, in this study $81 \%$ responded correctly by providing PMTCT intervention to HIV-positive pregnant women at their first antenatal consultation. ${ }^{26}$

This study showed that respondents had $71 \%$ correct responses on the management of newborns of HIV-positive women. However, available literature points to the contrary, where $73 \%$ of respondents thought that the newborns of HIV-infected women were already infected, and were unaware of riskreduction measures. ${ }^{19}$ Considering the endemicity and public health implications of HIV in SA, every HCW should be knowledgeable regarding all the guidelines involving HIV/AIDS management. Hence in our study the performance should be $100 \%$.

The relatively correct response in terms of the practices of PMTCT may be due to the high median years of practice (12). Even though $63 \%$ of the participants did not know the correct drug combinations and $79 \%$ did not know the correct doses, the ease of treatment provided by fixed-dose combinations may be one of the reasons for better practice scores amongst participants.

\section{Conclusions}

This study demonstrated the value of engaging the nursing fraternity as the front-line implementers of critical public health programmes such as the PMTCT, as their numbers are significantly higher than doctors'. The high levels of knowledge (94\%) of the PMTCT programme and generally satisfactory implementation bear witness to the emphasis placed by the health ministry on the reduction of HIV to meet the SDGs. Furthermore, the need for sustained exposure and training of health professionals in HIV management is demonstrated by the findings that profession and the mean years of practice (experience) had a statistically significant $(p<0.05)$ association with the knowledge and practice of PMTCT.

\section{References}

1. UNAIDS. Fact Sheet 2016 [homepage on the internet]. 2016 [cited 2016 Ma6 21]. Available from: www.unaids.org/en/resources/ factsheet

2. World Health Organization. Global report: UNAIDS report on the global AIDS epidemic. Geneva: World Health Organization; 2013.

3. Paintsil E, Andiman WA. Update on successes and challenges regarding mother-to-child transmission of HIV. NIH Public Access. 2009;21: 94-101.

4. United Nations. The Millennium Development Goals Report 2015 [report on the internet; cited 2016 Aug 11]. Available from: http:// www.un.org/millenniumgoals/2015_MDG_Report/pdf/MDG\%20 2015\%20rev\%20(July\%201).pdf 
5. United Nations. Sustainable Development Goals: post-2015development-agenda [report on the internet; cited 2016 Aug 11]. Available from: www.undp.org/content/undp/en/home/ sdgoverview/.

6. National Department of Health, South Africa \& South African National AIDS Council. Clinical Guideline. Prevention of mother to child transmission (PMTCT). Pretoria: Government Printer; 2010. p. 2010.

7. Fiscus SA, Adimora AA, Schoenbach VJ, et al. Perinatal HIV infection and the effect of zidovudine therapy on rural and urban counties. JAMA 1999;275(19): 1483-488.

8. Dorenbaum A, Cunningham CK, Gelber RD, et al. Two-dose intrapartum/newborn nevirapine and standard antiretroviral therapy to reduce perinatal HIV transmission: a randomized trial. JAMA 2002;288(2): 189-198. http://dx.doi.org/10.1001/jama.288.2.189

9. Barron P, Pillay $Y$, Doherty $T$, et al. Eliminating mother-to-child HIV transmission in South Africa. Bull WHO 2013;91(1):70-74.

10. Kermode M, Holmes W, Langkham B, et al. HIV-related knowledge, attitudes and risk perception amongst nurses, doctors and other healthcare workers in rural India. Indian J Med Res. 2005;122:258-64.

11. Igumbor J, Pengpid S, Obi L. Effect of exposure to clinicbased health education interventions on behavioural intention to prevent mother-to-child transmission of HIV infection. J Soc Aspects HIV/AIDS. 2006;3:394-402. http://dx.doi.org/10.1080/17290376.2006.9724865

12. Meyers T, Moultrie $H$, Naidoo K, et al. Challenges to pediatric HIV care and treatment in South Africa. J Infect Dis. 2007;196:S474-81. http://dx.doi.org/10.1086/524757

13. Department of Health, South Africa. The National Antenatal Sentinel HIV \& Herpes Simplex Type-2 Prevalence Survey in South Africa [report on the internet; cited 2016 Aug 11]. Available from: https:// www.health-e.org.za/wp-content/uploads/2014/05/ASHIVHerp_ Report2014_22May2014.pdf.

14. Health Systems Trust. District Health Barometer - 2014/2015 [homepage on the internet; cited 2016 Aug 11]. Available from: https://www.health-e.org.za/wp-content/uploads/2015/10/ Complete_DHB_2014_15.

15. Bouvier LF. Doctors and nurses: A demographic profile. Centre for Immigration Studies; 1998.

16. Umeh CN, Essien EJ, Ezedinachi EN, et al. Knowledge, beliefs and attitudes about HIV/AIDS-related issues, and the sources of knowledge among health care professionals in southern Nigeria. J R Soc Promo Health. 2008;128(5):233-9. http://dx.doi.org/10.1177/1466424008092793

17. Amoran OE, Ogunsola EO, Salako AO, et al. HIV/AIDS related home based care practices amongst primary health care workers in Ogun state. Nigeria. BMC Health Serv Res. 2012;12:112.

18. Nneka LM, Donna N. KAP of Healthcare providers towards prenatal HIV screening and prevention of Mother to child Transmission of HIV in Nigeria. Paper presented at the Annual Conference of Global Health Education Consortium; 2007.

19. Hentgen V, Jaueguiberry A, Andranatonadro V, et al. Knowledge, attitudes and practices of health personnel with regards to HIV/AIDS in Tamataye, Madagascar. Bull Soc Pathol. 2002;95(2):103-8.
20. Ndikom CM, Onibokun A. Knowledge and behaviour of nurse/ midwives in the prevention of vertical transmission of HIV in Owerri, Imo State, Nigeria: a cross-sectional study. BMC Nurs. 2007;6(1):1138. http://dx.doi.org/10.1186/1472-6955-6-9

21. Sadob AE, Fawole AO, Sadob WE, et al. Attitude of healthcare workers to HIV/AIDS. Afr J Reprod Health. 2006;10(1):39-46.

22. Pokharel N, Shrestha M, Lama S. Awareness on HIV/AIDS and prevention of mother to child transmission of HIV/AIDS amongst stake holders and people living with HIV/AIDS in Dharan municipality, Sunsari, Nepal. Int J Nurs Midwifery. 2011;4(2):21-4.

23. Palombi L, Marazzi MC, Voetberg A, et al. Treatment acceleration program and the experience of the DREAM program in prevention of mother-to-child transmission of HIV. AIDS. 2007;21(Suppl 4):S65. http://dx.doi.org/10.1097/01.aids.0000279708.09180.f5

24. Harms G, Schulze K, Moneta I, et al. Mother to child transmission of HIV and its prevention; awareness and knowledge in Uganda and Tanzania. SAHARA J. 2005;2(2):258-66. http://dx.doi.org/10.1080/17290376.2005.9724849

25. Mnyani CN, Mclntyre JA. Challenges to delivering quality care in a prevention of mother-to-child transmission of HIV programme in Soweto, South Africa. SA J HIV Med. 2013;14:64-9. http://dx.doi.org/10.7196/sajhivmed.902

26. Olges JR, Murphy BS, Caldwell G, et al. Testing practices and knowledge of HIV among prenatal care providers in a low Seroprevalence state. AIDS Patient Care STDS. 2007;21(3):187-94. http://dx.doi.org/10.1089/apc.2007.0095

27. Shapiro RL, Hughes MD, Ogwu A, et al. Antiretroviral regimens in pregnancy and breast-feeding in Botswana. $\mathrm{N}$ Engl J Med. 2010;362:2282. http://dx.doi.org/10.1056/NEJMoa0907736

28. Arendt V, Ndimubanzi P, Vyankandondera J, et al. AMATA study: effectiveness of antiretroviral therapy in breastfeeding mothers to prevent postnatal vertical transmission in Rwanda. Paper presented at 4th IAS Conference on HIV Pathogenesis, Treatment and Transmission; 2007; Sydney, Australia.

29. John GC, Kreiss J. Mother-to-child transmission of human immunodeficiency virus type 1. Epidemiol Rev. 1996;18:149-57. http://dx.doi.org/10.1093/oxfordjournals.epirev.a017922

30. Jamieson DJ, Sibailly TS, Sadek R, et al. HIV-1 viral load and other risk factors for mother-to-child transmission of HIV-1 in a breastfeeding population in Cote d'Ivoire. J AIDS. 2003;34:430.

31. Shaffer N, Chuachoowong R, Mock PA, et al. Short-course zidovudine for perinatal HIV-1 transmission in Bangkok, Thailand: a randomised controlled trial. Lancet. 1999;353:773-80. http://dx.doi.org/10.1016/S0140-6736(98)10411-7

32. Townsend CL, Byrne L, Cortina-Borja $M$, et al. Earlier initiation of ART and further decline in mother-to-child HIV transmission rates, 2000-2011. AIDS. 2014;28:1049-57. http://dx.doi.org/10.1097/QAD.0000000000000212

33. Msiri HE, Tadesse E, Muula AS. Are public antenatal clinics in Blantyre, Malawi ready to offer services for the prevention of vertical transmission of HIV? J AIDS 2008;22(18):2555-7.

Received: 31-05-2016 Accepted: 22-08-2016 